\title{
Conversações entre futuros professores de FLE : proposta de desenho para a prática on-line da interação oral na formação docente
}

\author{
Maria del Carmen de la Torre Aranda ${ }^{1}$ \\ Universidade de Brasília \\ carmenarand@gmail.com
}

Thomas Petit ${ }^{2}$

Universidade de Brasília

tyl.petit@gmail.com

Karina Fernandes ${ }^{3}$

Universidade de Brasília

kfleur@gmail.com

\section{Resumo}

Neste artigo apresentamos uma proposta de desenho de curso em ambientes on-line para o aperfeiçoamento da competência de interação oral na formação inicial de professores de línguas estrangeiras. O acompanhamento de estudantes no período de Estágio Supervisionado do Curso Letras - Francês da UnB permitiu-nos identificar lacunas nessa competência, a partir das quais pensamos numa alternativa curricular capaz de ampliar os espaços e tempos de prática da língua alvo em contexto real. Adotamos a metodologia de Pesquisa Baseada no Desenho pelas respostas que ela traz ao nosso objetivo de conceber um curso envolvendo tecnologia digital, interação oral e mediação humana, além do vínculo essencial que ela propõe entre desenho, pesquisa e prática. De acordo com a metodologia retida, apresentamos neste texto as etapas de análise, desenho, desenvolvimento e implementação do

\footnotetext{
${ }^{1}$ Professora Adjunta no Departamento de Línguas Estrangeiras e Tradução da UnB, Área de Francês.

${ }^{2}$ Doutorando na Faculdade de Educação da UnB.

${ }^{3}$ Mestre em Linguística Aplicada pelo Programa de Pós-graduação em Linguística Aplicada da UnB
} 
curso de extensão universitária Conversações entre futuros professores de FLE, oferecido desde 2013 em parceria com a Université de Poitiers (França).

Palavras-chave: Interação oral. Tecnologias digitais. Pesquisa baseada em desenho.

\section{Abstract}

In this paper, we present the proposal for the design of an online course that aims at improving oral interaction skills in the context of pre-service foreign languages teacher training. The support given to students during the French Language Degree Supervised Internship at UnB enabled us to identify shortcomings of this skill. As a result, we considered a curricular alternative to allow more space and time for the target language practice in real context settings. We adopted the Design-Based Research methodology, because of the answers that it brings to our aim of designing a course involving digital technology, oral interaction and mediation, as well as the essential link promoted between design, research and practice. According to this approach, we hereby present the analysis, design, development and implementation stages of the extension course "Conversations between pre-service French teachers", offered since 2013 in partnership with the University of Poitiers, France.

Keywords: Oral interaction. Digital technologies. Design-Based Research.

\section{Demandas da formação docente em compasso com a sociedade contemporânea}

A possibilidade do contato em tempo real com outras culturas, ultrapassando as distâncias geográficas, e do estabelecimento de relações sociais de troca por meio de uma língua comum aparece-nos como o ponto de partida para a concepção de uma prática contemporânea da interação oral em língua estrangeira na formação docente.

Trazendo para a área do ensino de línguas a reflexão de Moita Lopes (2008, p. 92) sobre uma agenda de investigação para a Linguística Aplicada, acreditamos que "a possibilidade de experimentar a vida de outros para além da vida local" que nos é dada pelo mundo atual, de "ser e ver outros virtualmente como também 'conversar' com pessoas que nunca vamos ver” (2008, p. 91), deve 
abrir caminhos para uma renovação da pesquisa e da prática didática ajustadas aos tempos de hoje e às suas demandas.

Vivemos desde os últimos vinte anos transformações profundas em vários espaços da sociedade: nas comunicações, em primeiro lugar, que passam a acontecer via Internet e tecnologias digitais, e em decorrência destas na vida profissional e pessoal, na economia e na política, na saúde, nas artes, na educação. A mobilidade acadêmica internacional torna-se uma realidade para muitos brasileiros e, com ela, o contato interpessoal com falantes de outras línguas em diferentes contextos sociais. Estas mudanças na sociedade têm impacto nas demandas em educação, e devem ser levadas em conta na formação docente. Em particular, no ensino de francês língua estrangeira (FLE) no contexto das Licenciaturas em Letras, área para a qual ajustaremos agora nosso foco.

Em um cenário ideal, os futuros professores de FLE chegariam ao final do Curso de Letras com habilidades suficientes para engajar-se com espontaneidade e segurança em uma produção oral individual ou em interação oral sobre um variado leque de assuntos relativos tanto à sua área de atuação como a outras áreas do conhecimento. Isso significaria ir além de um conhecimento sólido do léxico ou da sintaxe da língua que se preparam para ensinar dentro de pouco tempo, e alcançar uma atuação comunicativa clara e eficiente, conscientes dos usos que fazem da língua estrangeira e dos sentidos que esses usos conferem a seus textos (MARCUSCHI, 2009).

Essas habilidades de uso da língua estrangeira em contexto permitiriam aos jovens licenciandos, a nosso ver, entrarem em préserviço dispondo dos recursos linguístico-discursivos necessários para formar, por sua vez, falantes de língua estrangeira preparados para interagir em diferentes situações de contato interpessoal. Esse cenário não corresponde, no entanto, à realidade da educação de professores de línguas nas universidades públicas brasileiras, como apontado por Bonini, Oliveira e Tílio em Conversas com formadores de professores de línguas (ARAGÃO; SILVA, 2013), nem espelha o contexto da universidade em que atuamos.

De modo geral, os estudantes do Curso de Letras - Francês chegam hoje ao final da graduação com lacunas em suas habilidades comunicativas orais na língua estrangeira de eleição, sobretudo em interação. Possuem conhecimentos teóricos sobre a língua, mas nem 
sempre sabem como transpô-los para a prática, isto é, como adequar o uso da linguagem aos diferentes contextos sociointeracionais em que se veem implicados. Tais lacunas têm sido observadas, em particular, às vésperas do período de regência dos Estágios Supervisionados, quando os estudantes estagiários manifestam inseguranças reais diante do medo de falar errado ou de ensinar algo errado, cientes das implicações de sua atuação em um curso de nível básico (por onde entram em pré-serviço) para a construção de habilidades de comunicação em língua estrangeira de seus alunos em médio e longo prazo.

Para ajustar a formação desses futuros professores às atuais demandas profissionais da área, seria preciso engajar-nos em um projeto de reforma das metas e dos currículos de Letras, assim como da metodologia de ensino nas licenciaturas; seria preciso apostar menos fichas em um conhecimento aprofundado do material linguístico, e dar mais espaço a uma formação de professores habilitados a transitar por diferentes contextos socioculturais e suas diversas práticas concretas de linguagem, como o apontam os pesquisadores da Linguística Aplicada ao ensino de línguas Bonini, Eres Fernández e Tílio em entrevistas a Aragão e Silva (2013). Trata-se de um projeto robusto, a ser pensado e discutido em nível nacional, mas que aponta também para a necessidade de intervenções locais que possam ser implementadas e testadas no curto prazo.

No contexto local em que atuamos, a intervenção que nos parece mais tangível por ora é fazer o fator tempo trabalhar a nosso favor. Avançamos a hipótese segundo a qual o tempo possa estar situado na origem do problema, e agir simultaneamente como um fator regulador da prática da interação oral na formação em língua estrangeira.

As disciplinas de língua francesa oferecidas na Licenciatura em Letras têm o duplo objetivo de formar falantes proficientes de francês e ao mesmo tempo torná-los aptos a ensinar futuramente essa língua. Isto supõe tanto estudar a língua em seus aspectos fonológicos, lexicais, morfológicos, sintáticos, pragmáticos, quanto praticar seu funcionamento no discurso. Trata-se de um conteúdo programático de volume considerável a ser trabalhado em quatro ou seis horas de encontros semanais de turmas geralmente numerosas, ao longo de quatro anos da graduação. Não é raro, portanto, que os tempos dedicados à prática da interação verbal oral sejam comprimidos dentro 
desse quadro. A esta compressão do tempo na sala de aula some-se outra, de dimensão macro: aquela da vida contemporânea cujos espaços se veem multiplicados pelas tecnologias digitais.

De acordo com as reflexões propostas por Vani Kenski (2013) em sua recente obra Tecnologias e tempo docente, as múltiplas demandas da atual sociedade tecnológica impõem-nos um ritmo de vida acelerado e uma necessária reorganização do tempo para darmos conta da quantidade de tarefas assumidas. Citando Agnes Heller (1977), Kenski (2013, p. 29) lembra que não é o tempo que muda, mas sim o ritmo do tempo que muda em função dos períodos históricos, e que, “a vida, portanto, deve ser 'reorganizada' frequentemente”. Tratase não só de um aprender a reorganizar nossas vidas em função das urgências que cotidianamente roubam o lugar de outras menos urgentes, mas de desenvolvermos uma nova concepção de tempo que nos possibilite apreendê-lo segundo referenciais mais flexíveis para este período histórico.

Nesse cenário, cabe perguntar-nos de que maneira os estudantes estão lidando com as múltiplas exigências, calendários e prazos da vida acadêmica nesta sociedade tecnológica, muitas vezes paralelamente ao início de sua vida profissional. Encontram tempo para diferentes práticas da oralidade fora do contexto de formação acadêmica ou interlocutores dispostos a tentá-lo? $\mathrm{O}$ acesso a múltiplas fontes de informação e a exposição a práticas linguístico-discursivas situadas "para além da vida local", como dizíamos acima com Moita Lopes, é hoje uma realidade; mas, na maioria das vezes, essa exposição coloca o estudante apenas na posição de receptor de discursos. Olhando a questão do ponto de vista da pesquisa, parece-nos urgente que os formadores de professores de línguas busquemos alternativas de reorganização do tempo e da prática didática a fím de colocá-lo em posição de (co)produtores de discursos.

Ao discutir o conceito de urgência, Kenski (2013) apresenta-nos a proposta de Giovanni Gasparini (1995) de considerar duas dimensões relacionadas ao tempo que remetem às figuras da mitologia grega khronos e kairós. A dimensão khronos representa a inexorável passagem do tempo, a dimensão quantitativa do "tempo eterno e em movimento" (2013, p. 33), do tempo controlado. Já kairós representa a oportunidade, "o momento favorável", o tempo subjetivo. A autora remete, ainda, à opinião de Stewart Brand (2000) segundo a qual 
“estamos vivendo a 'era áurea de kairós', ou seja, do momento interior e oportuno, que deve ser aproveitado" (KENSKI, 2013, p. 34, destaques da autora). É desde a perspectiva de kairós que vemos o tempo agir como um fator regulador da prática da interação oral na formação em língua estrangeira.

O desenho de um espaço para a prática instrumentada da interação oral apresentado neste artigo parte do princípio que é possível romper, em certa medida, com a relação de causa e efeito que os elementos tempo dedicado à prática da interação oral e insegurança (legítima) presente nos discursos dos estudantes entretêm entre si. Ao expandir os espaços e tempos da prática mediada da interação oral levando-a para o ambiente on-line, torna-se possível colocar o estudante em uma situação de prática social real e espontânea da língua estrangeira. Trata-se, ainda, de expor o professor de línguas em formação inicial a uma atividade comunicativa que requererá a mobilização em tempo real de uma série de operações cognitivas, linguístico-discursivas e de estratégias de interação que o confrontarão de fato a uma das maiores especificidades da construção do texto falado em interação: os tempos de planejamento, de formulação e de realização são um só (KOCH, 2003). Os tempos dedicados à interação expandem-se para regular a prática do locutor estrangeiro de francês aos tempos próprios da fala em interação.

Estas reflexões foram o ponto de partida para a concepção do curso de extensão universitária Conversações entre futuros professores de FLE oferecido pelo Departamento de Línguas Estrangeiras e Tradução (LET) da Universidade de Brasília ${ }^{4}$ em parceria com a Faculdade de Letras e Línguas da Universidade de Poitiers (UP) desde 2013. A proposta de desenho do curso e a análise que apresentamos neste estudo referem-se à sua primeira edição, do segundo semestre letivo daquele ano. Antes de conhecer o desenho do curso, é importante precisar sob que ponto de vista abordamos a prática didática da interação oral.

\footnotetext{
${ }^{4}$ Curso oferecido pelo LET-UnB, fruto de uma parceria entre a professoras Maria del Carmen de la Torre Aranda (Área de Francês), o doutorando em Educação Thomas Petit (Faculdade de Educação, UnB), e Karina Fernandes, Mestre em Linguística Aplicada pelo Programa de Pós-graduação em Linguística Aplicada LET-UnB, membros do grupo de pesquisa TECLE, da mesma instituição.
} 
Maria del Carmen Aranda; Thomas Petit; Karina Fernandes

\section{Abordagem da interação oral on-line}

Toda formação em língua estrangeira se pauta, em primeiro lugar, pela concepção de língua com que o professor trabalha. Para a construção do Conversações entre futuros professores de FLE, partimos de uma abordagem interacionista que concebe a língua não como um sistema fechado que se impõe de dentro para fora, mas sim como uma atividade social interativa, um processo dialógico de construção de sentidos, assim como o propuseram Bakhtin e Volochínov (1929) em Marxismo e Filosofia da Linguagem.

Compreender a língua como interação significa dizer, além de que toda expressão verbal pressupõe a existência de um interlocutor, que nosso discurso é constantemente moldado em função desse interlocutor e juntamente com ele. Para Bakhtin e Volochínov,

toda palavra comporta duas faces. Ela é determinada tanto pelo fato de que procede de alguém, como pelo fato de que se dirige para alguém. Ela constitui justamente o produto da interação do locutor e do ouvinte (BAKHTIN; VOLOCHÍNOV, ([1929] 2009, p. 117, destaques dos autores).

Isto significa dizer que o modo como falamos reflete escolhas (lexicais, discursivas, linguísticas) feitas em função do nosso eu, é certo, do modo de ser e de se expressar de cada um, mas também em função do outro, da relação que se entretém com esse interlocutor (pessoal ou profissional, de maior ou menor proximidade), da imagem social que se deseja construir na interação, do contexto em que ela se dá (mais ou menos formal). Além, é claro, do posicionamento que se quer adotar acerca do tópico conversacional.

Veja-se tal princípio na definição de interação trazida por Kerbrat-Orecchioni que retivemos para este estudo:

Para que haja troca comunicativa, não basta que dois interlocutores (ou mais) falem de modo alternado; é ainda necessário que eles se falem, isto é, que os dois estejam "engajados" na troca, e que eles produzam sinais desse engajamento mútuo recorrendo a diversos procedimentos de 
validação interlocutória ${ }^{5}$ (KERBRAT-ORECCHIONI, 1996, p. 4, destaques no texto; tradução nossa).

Trata-se de um princípio fundamental da interação oral, que a referida autora (1996, p. 4, destaques no texto) traduz por "uma rede de influências mútuas", e que supõe o engajamento e a cooperação imediata dos interlocutores para que a comunicação efetivamente se sustente e cumpra sua finalidade comunicativa.

Na recente publicação Pour une didactique de l'oralité, Corinne Weber (2013) sugere que a prática da interação enquanto atividade social seja "dotada de virtudes" para a apropriação de uma segunda língua e, citando Pierre Bange (1992), atribui à interação o papel de "fator estruturante da linguagem" (WEBER, 2013, p. 72). Seguindo a mesma linha de pensamento, Simona Doehler (2000, p. 4, tradução nossa) afirma que "a abordagem interacionista [...] fundamenta-se na ideia que a interação social é constitutiva dos processos cognitivos, e até mesmo construtiva dos saberes e dos savoir-faire linguageiros e da própria identidade do aprendente" 6 .

Nosso desafio neste projeto foi fazer com que as interações orais pudessem ser ao mesmo tempo o lugar da prática em que são desenvolvidas habilidades e estratégias comunicativas bem como testadas sua eficácia (língua como meio), e o espaço propício à participação ativa dos sujeitos aprendentes na construção de sua própria aprendizagem, uma vez que é por meio delas que o grupo compartilharia seu entendimento do funcionamento da língua alvo (língua como objeto da aprendizagem).

O projeto Conversações entre futuros professores de FLE tem por objetivo geral promover a prática reflexiva da interação oral, em ambiente on-line, entre estudantes brasileiros do Curso de Letras -

${ }^{5}$ Pour qu'il y ait échange communicatif, il ne suffit pas que deux locuteurs (ou plus) parlent alternativement ; encore faut-il qu'ils se parlent, c'est-à-dire qu'ils soient tous deux "engagés" dans l'échange, et qu'ils produisent des signes de cet engagement mutuel, [...] en recourant à divers procédés de validation interlocutoire (KERBRAT-ORECCHIONI, 1996, p. 4).

${ }^{6} \mathrm{~L}$ 'approche interactionniste [...] se fonde sur l'idée que l'interaction sociale est constitutive des processus cognitifs, voire constructive des savoirs et des savoir-faire langagiers et de l'identité même de l'apprenant (DOEHLER, 2000, p. 4). 
Francês da UnB e estudantes franceses (ou estrangeiros considerados locutores proficientes) do Master Didactique des Langues et du FLES da UP. A este objetivo geral somam-se outros mais específicos:

- $\quad$ oferecer um espaço propício à interação em francês em contexto real;

- $\quad$ desenvolver habilidades de autorreflexão sobre a própria interação oral;

- passar da autorreflexão à reflexão colaborativa entre pares.

Certamente, o desenvolvimento de habilidades de interação oral é um processo que ocorre ao longo de toda uma vida de prática da língua estrangeira, e o que se pode considerar como aprendizagem efetiva na duração de um semestre é o despertar de uma consciência dos locutores estrangeiros sobre os efeitos de sentido criados em seu discurso em razão de suas escolhas linguísticas. A criação de um ambiente on-line para a prática do oral em busca de tal objetivo requer uma abordagem metodológica fundamentada e uma escolha criteriosa de recursos tecnológicos para a implementação do desenho do curso.

Apresentamos, a seguir, a abordagem metodológica retida para o projeto, assim como o ciclo iterativo de análise, desenho, desenvolvimento e implementação posto em prática na primeira edição do projeto. Nessa edição, estudantes brasileiros e franceses realizaram uma série de conversações on-line por meio da ferramenta de videoconferência Hangouts, acerca de temas centrais da didática de línguas e de sua experiência inicial no ensino do francês língua estrangeira.

\section{A Pesquisa Baseada em Desenho}

Neste estudo, adotamos a metodologia de Pesquisa Baseada em Desenho (PBD), também conhecida no mundo anglo-saxão como Design-Based Research. Wang e Hannafin a definem como

\footnotetext{
${ }^{7}$ Mestrado em Didática das Línguas e do Frances Língua Estrangeira e Segunda (FLES).
} 
uma metodologia sistemática, mas flexível, cujo objetivo é melhorar práticas educacionais através do ciclo iterativo de análise, desenho, desenvolvimento e implementação, baseada na colaboração entre pesquisadores e praticantes em contextos do mundo real, levando a princípios e teorias de desenho sensíveis ao contexto (WANG; HANNAFIN, 2005, p. 6, tradução nossa) ${ }^{8}$.

Trata-se de uma abordagem metodológica cada vez mais adotada em pesquisas envolvendo cursos mediados por tecnologias digitais, pelas respostas que oferece à concepção dos mesmos. Para nós, ela representa uma alternativa que merece atenção por vários motivos.

Em primeiro lugar, interessou-nos a convergência entre $o$ desenho, a pesquisa e a prática, ressaltada por Wang e Hannafin (2005). O equilíbrio entre estes três elementos, no âmbito da extensão universitária em geral, e do Conversações entre futuros professores de FLE mais especificamente, parecem-nos essenciais uma vez que ele nos permite estabelecer uma relação intrínseca entre o curso, o ensino e a pesquisa. Além dessa convergência, os autores referidos chamam a nossa atenção para cinco características principais da PBD.

A primeira delas refere-se à sua dimensão pragmática, que corresponde justamente à relação entre teoria e prática. De acordo com a segunda característica, entendemos que a PBD é uma metodologia fundamentada. Apoia-se em teorias de aprendizagem integradas durante o período de concepção do projeto pela equipe, e é ancorada em contextos do mundo real. Neste sentido, conforme explica o Design-Based Research Collective (2003), a relação estabelecida entre desenho, pesquisa e parâmetros da vida real pode promover inovações no contexto de intervenção. Todavia, além destes aspectos, a análise de desenhos apresentados e adotados em outras pesquisas faz parte, também, desta fundamentação.

${ }^{8}$ [We define design-based research as] a systematic but flexible methodology aimed to improve educational practices through iterative analysis, design, development, and implementation, based on collaboration among researchers and practitioners in real-world settings, and leading to contextually-sensitive design principles and theories (WANG; HANNAFIN, 2005). 
A terceira característica da metodologia de pesquisa baseada no desenho, como vimos há pouco em sua definição, consiste na interatividade, na iteratividade e na flexibilidade. É interativa na medida em que implica uma colaboração entre os pesquisadores e os participantes em um ciclo iterativo envolvendo análise, desenho, desenvolvimento e implementação (Figura 1). Finalmente, é flexível na medida em que o desenho pode ser alterado durante a sua implementação, a partir dos dados já observados ou da emergência de novos parâmetros ou demandas internas à formação. No âmbito de um curso de extensão universitária que pode ter reedições ao longo de anos, a flexibilidade é por nós vista como uma mais-valia metodológica.

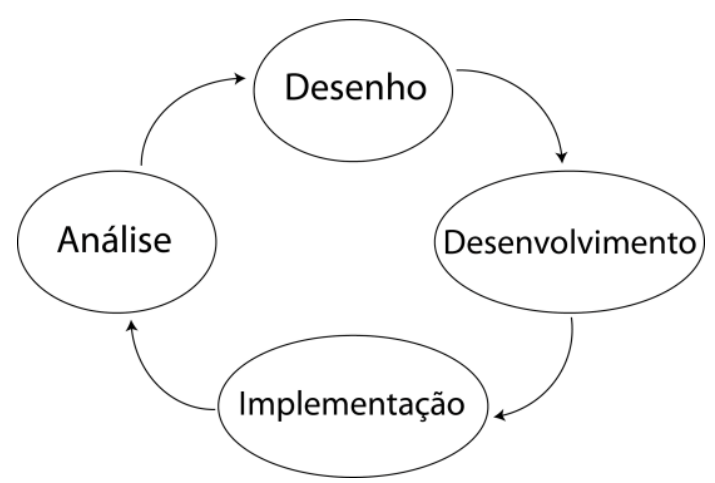

Figura 1 - Ilustração do ciclo iterativo da PBD

A quarta característica da PBD é sua dimensão integrativa. Isto se deve ao fato de a metodologia lançar mão de uma combinação de métodos de pesquisa, tanto quantitativos como qualitativos, a fim de serem promovidas mais objetividade, mais validade e mais aplicabilidade no processo investigativo. Finalmente, a PBD se caracteriza pela sua dimensão contextual, o que significa que os resultados estão vinculados ao desenho inicial e aos parâmetros do contexto geral de pesquisa. A PBD, efetivamente, se desenvolve numa abordagem sistêmica, considerando-se cada elemento do macro contexto como variável importante, de acordo com o que preconizam alguns teóricos da didática do francês língua estrangeira (MANGENOT, 2000; PUREN, 2001). 


\section{Uma proposta de desenho para a prática da interação oral: Conversações entre futuros professores de FLE}

\subsection{Análise}

A partir da idealização do Conversações entre futuros professores de FLE acima explicitada, a avaliação e a escolha das ferramentas e ambientes digitais que melhor nos apoiariam para o desenho do curso impuseram-se como o primeiro passo na etapa de análise do ciclo iterativo da PBD. Para responder ao objetivo geral do curso de promover uma interação oral on-line seguida de uma prática de autorreflexão, as ferramentas e os ambientes on-line deviam nos permitir realizar as seguintes atividades:

- $\quad$ conversações síncronas entre estudantes da UnB e da UP;

- $\quad$ gravação das conversações;

- compartilhamento dos arquivos em áudio (textos orais das conversações);

- compartilhamento coletivo das reflexões sobre as interações orais.

Em um primeiro momento, havíamos pensado em usar o programa de videoconferência Skype para as conversações, o aplicativo Camtasia para a gravação destas em vídeo, o ambiente Dropbox para compartilhá-las com os alunos, e a rede social on-line Facebook como espaço de postagem e compartilhamento das reflexões sobre os textos orais. No entanto, seguindo aconselhamento da equipe de suporte técnico do nosso departamento na universidade, o programa Skype foi posteriormente desconsiderado devido à alta exigência de qualidade de conexão à Internet para a manutenção da comunicação síncrona. Esta mudança nos fez rever não apenas a escolha da ferramenta para a realização das conversações, atividade que inicia a sequência didática, mas também a de dois dos ambientes inicialmente imaginados para a realização das atividades subsequentes. Assim, em um segundo momento, optamos por usar as seguintes ferramentas:

- Google Hangouts para a realização das conversações;

- Camtasia, mantido para a gravação;

- Google Drive para o compartilhamento dos arquivos em áudio; 
- Google+ $(G+)$ para a postagem das reflexões.

Vejamos estas escolhas de perto. Para as conversações on-line, o Google Hangouts foi preferido ao Skype pela sua facilidade de uso e de instalação, assim como por sua menor exigência em termos de velocidade de conexão à Internet. Esta escolha nos permitia antecipar e minimizar eventuais problemas de conexão nas duas instituições participantes. Para a coleta de dados, mantivemos o Camtasia porque o aplicativo permite ter tanto o áudio das conversações quanto o registro em vídeo do que acontece na tela do computador. A quantidade de espaço oferecida gratuitamente pelos serviços de hospedagem e compartilhamento de arquivos áudio analisados foi decisiva para optarmos por disponibilizar as gravações no Google Drive, ao invés de fazê-lo com o auxílio do Dropbox. Por último, como a reorganização dos recursos apontava para a concentração das atividades em um mesmo ambiente, avaliamos a adequação da rede social $G+$ ao objetivo de termos um espaço coletivo para compartilhamento das reflexões sobre as interações orais.

Inúmeras experiências de uso pedagógico da rede social Facebook vêm sendo publicadas, no Brasil e no mundo, tanto na educação em geral quanto no ensino e na aprendizagem de línguas estrangeiras em particular. Porém, não encontramos justificativas satisfatórias da adequação de tal ferramenta a objetivos pedagógicos específicos. Após uma análise comparativa entre essa rede social e o $G+$, consideramos que esta última era a mais adequada por duas razões principais. Primeiro, ao contrário do Facebook, no $G+$ é possível compartilhar vídeos imediatamente após gravá-los com a própria ferramenta de postagem do ambiente. Esse elemento foi determinante na nossa escolha: dado que nosso objetivo é trabalhar as habilidades orais dos estudantes, eles teriam uma oportunidade a mais de expressar-se por meio de textos orais. A segunda razão tange à formalidade do ambiente. De fato, o Facebook representa, a nosso ver, um ambiente muito vinculado a um uso informal, e pareceu-nos que a ferramenta $G+$, menos associada a esse uso, a revestiria de maior caráter acadêmico.

Além dessas duas razões a favor do $G+$, o ambiente oferece as mesmas opções que haviam chamado nossa atenção ao considerar, a princípio, o uso do Facebook: a possibilidade de criar grupos privados, o fato de poder identificar um participante do grupo com o sistema de 
tags, de organizar eventos com o calendário, de publicar postagens e comentá-las de forma dialógica e, ainda, de clicar nos botões “+1" equivalente do "curtir" no Facebook - o que é, a nosso ver, uma demonstração de presença no ambiente on-line.

Por fim, após esta análise criteriosa da adequação das ferramentas ao desenho e aos objetivos do Conversações entre futuros professores de FLE, chegamos a uma concentração das ferramentas e, portanto, das atividades do curso, no ambiente Google. Isso implicou uma facilitação não negligenciável das etapas que compõem o curso, pois reduziu os requisitos técnicos a apenas a criação de uma conta Gmail - caso os estudantes ainda não tivessem uma - ao invés da criação de uma conta para cada um dos ambientes pensados no começo.

De acordo com a dimensão fundamentada da PBD, ressaltada por Wang e Hannafin (2005), procedemos também à análise de desenhos já existentes voltados para a prática de língua estrangeira. No contexto brasileiro, é imprescindível remeter-nos ao projeto Teletandem Brasil: línguas estrangeiras para todos, idealizado em 2006 por Telles na UNESP de Assis e que conta, em sua história, com uma importante parceria de universidades francesas tais como Lille 3 e a Université Lumière Lyon 2 (TELLES, 2010). Já no contexto específico do ensino e aprendizagem do FLE, o projeto internacional Le français en (première) ligne (F1L), em constante reedição desde 2002 (DEVELOTTE; GUICHON; KERN, 2008), impôs-se como um dos mais relevantes na área na última década.

Além desses, o desenho do projeto de pesquisa-ação Cefradis (Cours pilote de français avancé à distance ${ }^{9}$ ) (ARANDA, 2011) também foi analisado, e é considerado por nós como o desenho inicial do Conversações entre futuros professores de FLE. Para a análise do estudo aqui apresentado, levamos em conta especialmente a revisão dos projetos específicos da área do francês língua estrangeira, valendonos também de uma comparação do F1L feita por seus próprios autores

${ }^{9} \mathrm{O}$ Cefradis (Curso piloto de francês avançado a distância) foi ofertado como curso livre a estudantes de $3^{\circ}$ ano de Letras-Francês da FFLCH-USP como parte de pesquisa de doutoramento em Estudos Linguísticos, Literários e Tradutológicos em Francês pela Universidade de São Paulo (ARANDA, 2011). 
com projetos similares tais como o Télé-tandem e o Cultura (DEVELOTTE; GUICHON; KERN, 2008).

Desde a perspectiva da pesquisa, entendemos que o desenho do Conversações, quando comparado aos projetos mencionados, possui caráter de inovação por dois motivos: pela relação entre os interlocutores que constituem seu público alvo, e por seu desenho, que privilegia na mesma medida a prática da interação oral em contexto de formação de professores e a prática da autorreflexão.

Além de diversificar os contextos de prática da oralidade, as tecnologias digitais nos propiciam hoje uma abordagem mais reflexiva da aprendizagem de línguas. A facilidade com que se registram, armazenam e compartilham os textos orais das interações nos permite conceber desenhos de cursos em língua estrangeira que abram espaço para a autorreflexão dos sujeitos aprendentes.

Do Cefradis resgatamos a experiência da prática reflexiva sobre os textos orais, cujos desenho e uso de ferramentas nos mostraram ser viável construí-la no espaço on-line de forma colaborativa, seja ela bidirecional (professor-estudante) ou multidirecional (professorestudante-estudante). Nesse projeto, estudantes brasileiros de Letras Francês com o mesmo nível de proficiência em francês interagiam entre si em ambiente on-line para aperfeiçoar suas habilidades de comunicação oral: após uma etapa de interação entre professora e estudante para apropriação destes das ferramentas digitais, as interações se davam entre estudante e estudante, com feedback sobre os textos produzidos proposto pela professora mediadora.

No Conversações, diferentemente dos projetos mencionados acima que envolviam interações aprendente-aprendente (Teletandem, Cultura, Cefradis) ou aprendente-futuro professor de FLE (F1L), o nosso curso, como seu nome o indica, propõe conversações entre futuros professores de FLE. Isto implica uma diferença fundamental na medida em que os estudantes brasileiros não são considerados como aprendentes, mas como locutores de uma língua que será, dentro de pouco tempo, o objeto de sua prática profissional. Além do objetivo linguístico-discursivo do lado brasileiro, e diferentemente do F1L que também envolvia futuros profissionais, a especificidade do Conversações reside no fato de que os dois interlocutores das conversações têm um objetivo pedagógico comum: compartilhar seus 
pontos de vista e discutir questões teóricas e práticas da didática de línguas estrangeiras.

De um lado da tela, a habilidade linguística dos interlocutores franceses deveria ser percebida como uma vantagem não para eles mesmos, mas para os brasileiros: uma oportunidade de interagir com um locutor que vive cotidianamente a realidade discursiva da língua alvo, de observar os usos da linguagem e a construção de enunciados para constituir-se um leque de exemplos de uso da língua falada por locutores proficientes em contexto francófono. Do outro, o conhecimento teórico dos estudantes brasileiros de Estágio Supervisionado em período de pré-serviço também deveria ser visto como um ganho para os pares franceses, que teriam a oportunidade de conhecer opiniões formadas a partir da literatura discutida em uma universidade brasileira, de ouvir as representações sobre o ensino do FLE desde a perspectiva do estudante que vive a realidade de um país não-francófono. Além disso, os estudantes franceses, também em período de pré-serviço, teriam a oportunidade de experimentar os desafios da interação verbal com interlocutores ainda em fase de ajustamento de suas habilidades linguístico-discursivas em língua estrangeira - os mesmos desafios que vivenciarão logo de sua entrada em sala de aula como professores.

Essa pareceu-nos ser a configuração ideal para uma relação social de troca por meio da língua entre estudantes de diferentes países e contextos socioculturais que propicie uma aprendizagem efetiva dos dois lados do oceano.

\subsection{Desenho}

A partir da abordagem teórica e da etapa de análise apresentadas previamente, pudemos proceder à elaboração do desenho do Conversações entre futuros professores de FLE que, naturalmente, se esboçava desde a etapa de concepção do curso em discussão com o coordenador do projeto na Universidade de Poitiers.

$\mathrm{Na}$ figura 2, ilustramos a sequência de aprendizagem do curso a fim de propor um modelo aplicável em contextos similares. Com ela, vemos como funciona uma sequência de aprendizagem, como cenário ideal de atividades previstas do lado da UnB, a partir da atividade inicial que é a conversação. Três momentos representam o 
planejamento dessa sequência, de acordo com os objetivos determinados a priori. A partir deles, delineia-se um roteiro que também corresponde ao uso de três ambientes tecnológicos diferentes, nos quais as atividades de aprendizagem vão ser distintas. Três sujeitos intervêm na sequência: o estudante da UP, o estudante da UnB e o mediador da UnB.

A sequência de aprendizagem do curso começa no ambiente Hangouts, a ferramenta usada para a videoconferência. $\mathrm{O}$ mediador dá início à atividade, propondo um tópico de conversação acerca das primeiras dificuldades que os estudantes deverão encontrar no ensino do FLE (equilíbrio entre língua materna e língua estrangeira junto a iniciantes, tradução ou explicação, metodologia voltada para a gramática ou para as habilidades comunicativas, interculturalidade etc.), e logo retira-se da interação. A partir desta proposta, desenvolvese a conversação entre a dupla de estudantes (UnB + UP) que propõem e discutem seus pontos de vista durante 30 minutos.

Embora permaneça conectado o tempo todo na conversa, o mediador ocupa os bastidores da interação assumindo um duplo papel: ora mais técnico, cuidando do registro da conversação e garantindo a permanência dos interlocutores francês e brasileiro em linha caso se perca a conexão à rede, ora mais acadêmico, na posição de ouvinte, já fazendo anotações preliminares de elementos textuais que poderão ser discutidos ulteriormente nas etapa de autorreflexão e feedback.

No segundo momento, o mediador disponibiliza a gravação no Google Drive, e em paralelo incentiva o estudante da UnB a refletir sobre o conteúdo, seja linguístico seja discursivo, da conversação. Isso é feito mediante a mensagem de notificação de compartilhamento de arquivo, enviado ao e-mail do estudante pelo Drive. Em seguida, na sequência lógica imaginada para este desenho, o estudante da UnB ouve a conversação e desenvolve sua autorreflexão. É importante ressaltar que o estudante da UP intervém apenas no primeiro momento da sequência, durante a atividade de conversação. As outras atividades têm continuidade de forma independente, em cada universidade, a partir deste segundo momento. No caso da UnB, ele corresponde ao objetivo de autorreflexão sobre a interação oral, a fim de desenvolver no estudante um início de tomada de consciência sobre os pontos positivos e as lacunas presentes em seu discurso. 
Conversações entre futuros professores de FLE...

\section{CONVERSAÇÃO - Google Hangouts (+ GRAVAÇÃO- Audacity)}

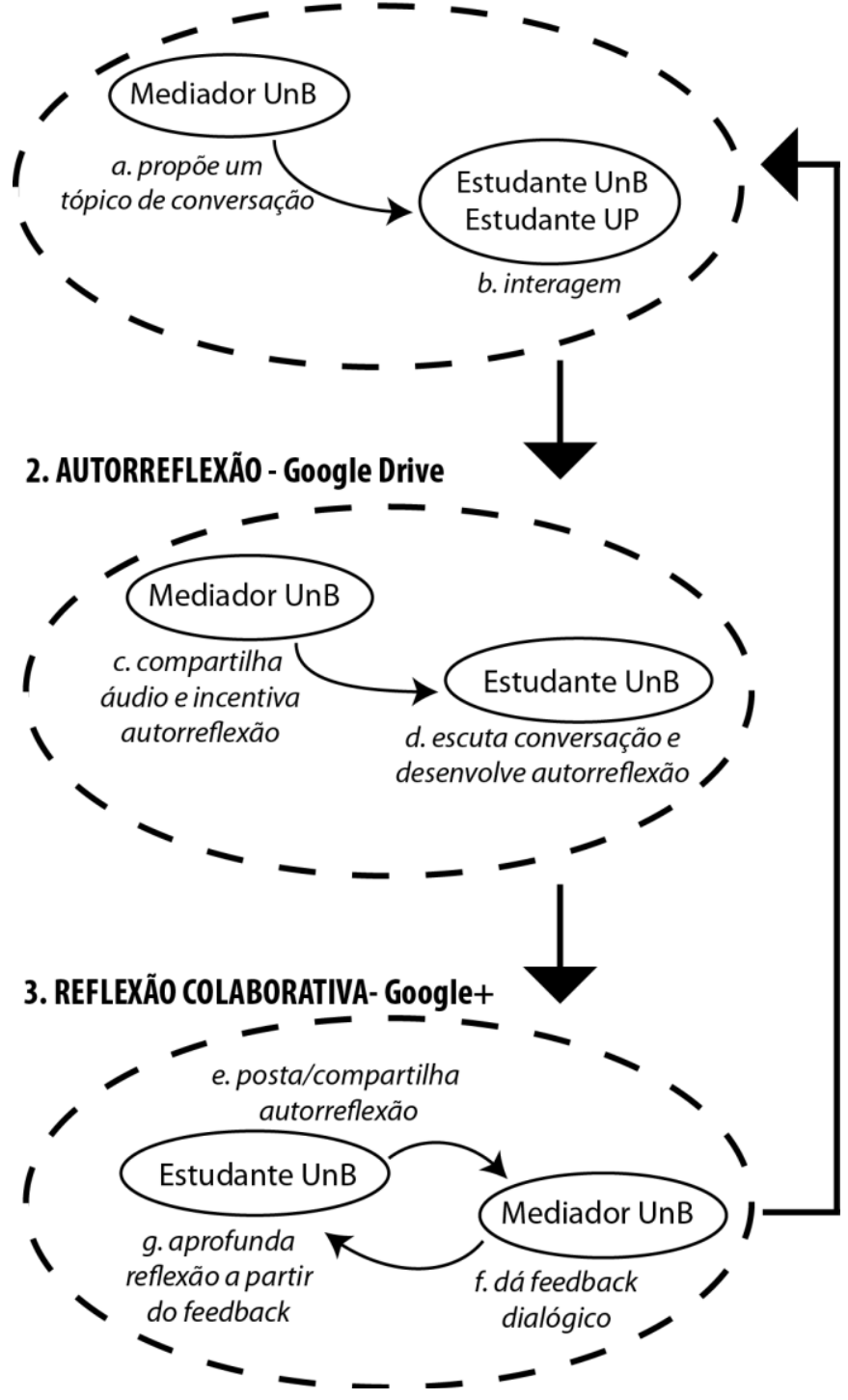

Figura 2: Organização de uma sequência de aprendizagem do Conversações entre futuros professores de FLE 
O objetivo de desenvolver a prática da reflexão colaborativa compõe o terceiro momento da sequência de aprendizagem. As atividades acontecem na comunidade privada do $G+$, com acesso restrito aos estudantes e mediadores da UnB. O estudante posta e compartilha a sua autorreflexão na linha do tempo do ambiente, de acordo com um prazo proposto pelo mediador. Esta autorreflexão pode ser tanto oral - através da gravação de um vídeo, como mencionado anteriormente - como escrita.

A partir da postagem do estudante começa a interação com o mediador, que faz comentários sob a forma de feedback dialógico apoiando-se em estratégias de abrandamento e de polidez linguística, para a preservação da face dos estudantes, elaboradas a partir de elementos da pragmática linguística e da Análise da Conversação (KERBRAT-ORECHIONNI, 2001). Por dialógico, entendemos que o próprio feedback deva permitir que a autorreflexão inicial seja aprofundada de forma colaborativa entre o estudante, o mediador, e eventualmente os outros participantes, uma vez que as postagens podem ser ouvidas ou lidas por todos. A autorreflexão, o feedback dialógico e a(s) resposta(s) do(s) estudante(s) representam, assim, o encerramento do ciclo da sequência de aprendizagem, que se reinicia a partir da próxima conversação.

A dimensão metacognitiva é fundamental neste último momento da sequência de aprendizagem. Efetivamente, nem sempre os estudantes têm a autonomia e o distanciamento suficientes para desenvolverem uma autorreflexão sobre seu próprio discurso oral em língua estrangeira. É papel do mediador orientá-los e ajudá-los nesse processo de autonomização e empoderamento sobre seu próprio processo de aprendizagem.

\subsection{Desenvolvimento e implementação}

Um projeto que envolve participantes de dois diferentes países funcionando cada um em um fuso horário, e que depende de uma série de recursos tecnológicos funcionando bem, conectados à rede Internet ou não, gratuitos ou não, traz invariavelmente surpresas em sua etapa de desenvolvimento e implementação. 
Nesta etapa, tivemos que lidar com a complexidade que tal parceria implicava: a diferença de horários entre o Brasil e a França para as conversações, cujo calendário foi alterado duas vezes para passar aos horários de verão e de inverno nos respectivos países; a organização dos cinco pares de interlocutores de cada lado do oceano; os testes de conexão e das ferramentas para otimizar as condições de interação; a organização dos tópicos didáticos de conversação em acordo com as propostas feitas também por Poitiers.

Quanto ao aspecto técnico do desenvolvimento do curso, a equipe da UnB (composta por apenas três professores-mediadores) organizou todos os testes de uso das ferramentas. Testes do Hangouts foram realizados em diferentes momentos antes da implementação do curso, inclusive com os estudantes, para que se apropriassem da ferramenta. Foi aberta a comunidade privada no $G+$ e apresentada aos estudantes em um primeiro encontro presencial, além de serem testadas suas ferramentas em contexto real, já repertoriadas na etapa de análise apresentada anteriormente. Finalmente, procedemos a testes de gravação das conversações. Esta foi uma etapa fundamental na medida em que esses registros representavam não apenas o material textual a partir do qual seria feita a autorreflexão, mas também dados de pesquisa cruciais a serem analisados posteriormente pelas equipes de Poitiers e Brasília. O aplicativo Camtasia acabou sendo substituído na segunda metade do projeto, devido a problemas encontrados no registro simultâneo do vídeo e do áudio e também por se tratar de um programa proprietário que usávamos em modo teste para explorar suas possibilidades. Optamos então por guardar o registro das interações apenas em áudio, por meio do aplicativo Audacity, cujo uso era familiar aos três mediadores. Novas análises de ferramentas para o registro das conversações impõem-se para a próxima edição do Conversações.

Durante a implementação do curso, houve uma grande parte de organização que concerniu, às vezes, apenas o grupo da UnB por tratar-se de aspectos relativos à sequência de aprendizagem que se revelaram enquanto acontecia o curso, o que nos levou a pequenos ajustes, de acordo com a flexibilidade permitida pela metodologia PBD. Ainda, por questões administrativas, o curso foi divido em 2 módulos, que corresponderam, em decorrência desses ajustes, a duas modalidades diferentes: híbrida e a distância. 
No módulo 1, em modalidade híbrida, estudantes e mediadores reuniam-se em um laboratório multimídia na UnB, onde dispúnhamos dos recursos e conexão necessários para a atividade de conversação. Mas a partir de certo ponto, mediadores e estudantes concordamos que impor um único horário era um limite desnecessário, tendo em vista a flexibilidade de espaço e de tempo possibilitadas pelas tecnologias digitais - como não resgatar a figura de kairós e agarrar a oportunidade que nos oferece? Assim passamos à modalidade a distância no módulo 2, com estudantes da UnB e da UP conectando-se desde um lugar de sua preferência.

A mudança para a modalidade a distância levou a uma nova organização do tempo khronos. Fez-se necessário confirmar a cada semana as disponibilidades de cada dupla de alunos e do mediador que os acompanharia nas conversações para assegurar-nos da realização das conversações, e atualizar semanalmente as agendas no ambiente $G+$, o que expandiu negativamente o tempo de trabalho e gestão do curso dos professores mediadores.

Esse passo foi dado após uma roda de conversa presencial realizada em uma semana de pausa entre os dois módulos, a partir da qual trouxemos outros ajustes ao desenho, relativos a seus aspectos práticos e de pesquisa, em função das narrativas dos estudantes. Nesta roda de conversa, eles relataram certa insegurança em tomar a iniciativa da autorreflexão, por receio da exposição (perda da face) em ambiente compartilhado com outros colegas. Efetivamente, durante o módulo 1, os mediadores fomos os que mais postamos vídeos no ambiente, como tutoriais de uso dos recursos e mensagens de incentivo à autorreflexão dos alunos. Entretanto, apenas um participante teve a iniciativa de postar sua primeira autorreflexão em vídeo. Entendemos também que nosso uso do ambiente para mostrar aos estudantes como ele funcionava, resultou, ao contrário do imaginado, numa compressão do espaço para a expressão deles. No módulo 2, deixamos a comunidade do $G+$ mais livre de nossas postagem em vídeo, preferindo comunicar-nos com os estudantes por meio de posts em texto escrito. O número de autorreflexões postadas pelos estudantes passou de um a sete. Em resposta, seis feedback elaborados pelos mediadores foram postados no $G+$, dando lugar, por sua vez, a apenas três reações de estudantes: dados bastante relevantes que certamente trarão implicações no redesenho da segunda edição do projeto. 
De fato, as "surpresas" que encontramos nesta etapa do projeto representam os elementos invariavelmente presentes em qualquer intervenção humana de mudança que não se permitem controlar $a$ priori. Aprender a lidar com eles só faz enriquecer a pesquisa e a prática, pois para levá-las a cabo é necessário proceder a novas e repetidas análises e redesenhos, mantendo assim o ciclo iterativo da PBD em movimento constante.

\section{Caminhando em direção a novos fluxos de discurso}

A reflexão que aqui trouxemos sobre o desenho do Conversações deixa-nos satisfeitos quanto aos resultados obtidos em sua primeira edição, e também otimistas quanto à evolução do projeto, atualmente em fase de organização da sua segunda edição. Buscamos, com ela, propor um início de discussão sobre a construção de um espaço de conversação em língua falada destinado à formação de futuros professores de línguas que possa ser transposto, aplicado e testado em outros contextos locais. Nesse sentido, o estudo pode ser visto como uma proposta de reflexão primordial sobre a necessidade de modelos de uso das tecnologias digitais para esse fim.

As adaptações trazidas ao desenho da primeira edição do projeto, durante suas etapas de desenvolvimento e implementação, constituíram uma resposta tanto às narrativas do estudantes coletadas na roda de conversa quanto às necessidades ou liberdades conferidas pelas tecnologias - o que caracteriza o projeto como um ciclo interativo, iterativo e flexível. Mas, para nós, elas ficam em aberto como questões que deverão ser repensadas do ponto de vista da investigação e reavaliadas a partir de novas práticas. Compreendemos que as questões concernentes ao aparato tecnológico implicarão inevitável e repetidamente novos questionamentos e atualizações, posto que a ferramenta em si tem uma esperança de vida curta - o $M S N$ foi usado no F1L, o Skype no Cefradis, o Hangouts na primeira edição do Conversações entre futuros professores de FLE - e seguirá evoluindo à medida que o tempo passar.

O foco não está, portanto, na ferramenta, mas sim na construção de um modelo de organização do espaço conversacional pautado por uma relação lógica entre o objetivo final visado e os meios empregados 
para atingi-lo. Essa é uma questão a ser tratada do ponto de vista da investigação, com foco urgente na mediação pedagógica, para que possamos abordar a formação de professores de línguas dentro da perspectiva da modernidade.

$\mathrm{Na}$ roda de conversa, os estudantes brasileiros envolvidos no projeto relataram uma satisfação enorme quanto à oportunidade - a primeira, para a maior parte deles - de poder engajar-se em uma conversação real com um interlocutor que vive cotidianamente a realidade discursiva e cultural da língua alvo. Isso reafirma nossa hipótese de expansão dos tempos dedicados à prática da interação oral por meio da comunicação mediada por computador, que abre hoje caminhos talvez inéditos para a criação de novos fluxos de discurso que atravessam as fronteiras nacionais. No entanto, como discutido ao longo do estudo, os espaços dedicados à prática da autorreflexão ainda carecem ser melhor explorados, a fim de desenvolver a tomada de consciência dos futuros professores sobre seus usos da língua estrangeira. Será preciso reavaliar o papel do mediador na próxima edição do projeto, em diálogo com os estudantes, a fim de melhor medir sua ação de incentivo à reflexão e construir uma comunidade de interação reflexiva em que se ajustem os espaços ocupados por cada um de seus membros. Que kairós siga trabalhando a nosso favor.

\section{Referências}

ARAGÃO, Rodrigo. C.; SILVA, Kleber. A. da; (Orgs.) Conversas com formadores de professores de línguas: avanços e desafios. Campinas: Pontes Editores, 2013.

ARANDA, Maria del Carmen de la Torre. Interações orais online no ensino do francês língua estrangeira: o projeto Cefradis. 2011. 317 p. Tese (Doutorado em Língua e Literatura Francesa) - Faculdade de Filosofia, Letras e Ciências Humanas, Universidade de São Paulo, São Paulo, 2011. Disponível em: <http://www.teses.usp.br/teses/disponiveis/8/8146/tde-24082011141810/>. Acesso em: 2015-05-24. 
BAKHTIN, Mikhail; VOLOCHÍNOV, Valentin N. A interação verbal. In: Marxismo e filosofia da linguagem: problemas fundamentais do método sociológico da linguagem. Tradução Michel Lahud e Yara Frateschi Vieira. São Paulo: Hucitec, [1929] 2009. p. 114-132.

DESIGN-BASED RESEARCH COLLECTIVE. Design-based research: an emerging paradigm for educational inquiry. Educational Researcher, v. 32, n. 1, p. 5-8, jan.-fev. 2003. Disponível em: <http://edr.sagepub.com/content/32/1/5.short >. Acesso em: 22 set. 2013.

DEVELOTTE, Christine; GUICHON, Nicolas; KERN, Richard. "Allô Berkeley ? Ici Lyon... vous nous voyez bien ?" Étude d'un dispositif de formation en ligne synchrone franco-américain à travers les discours de ses usagers. Alsic, v. 11, n. 2, p. 129-156, 2008. Disponível em: <http://alsic.revues.org/892>. Acesso em: 17 jun. 2014.

DOEHLER, Simona P. Approches interactionnistes de l'acquisition des langues étrangères : concepts, recherches, perspectives. Acquisition et interaction en langue étrangère, n. 12, p. 1-15, 2000. Disponível em: <http://aile.revues.org/934>. Acesso em: 5 fev. 2014.

KENSKI, Vani M. Tecnologias e tempo docente. Campinas: Papirus, 2013.

KERBRAT-ORECCHIONI, Catherine. La conversation. Paris: Éditions du Seuil, 1996.

KERBRAT-ORECCHIONI, Catherine. Les actes de langage dans le discours :théorie et fonctionnement. Paris : Nathan Université, 2001.

KOCH, Ingedore V. O texto e a construção dos sentidos. São Paulo: Contexto, [1997] 2003.

MANGENOT, François. L'intégration des TIC dans une perspective systémique. Les Langues Modernes, v. 94, n. 3, p. 38-44, 2000. Disponível em: <http://cat.inist.fr/?aModele=afficheN\&cpsidt=1155470>. Acesso em: 01 fev. 2012. 
MARCUSCHI, Luiz A. Produção textual, análise de gêneros e compreensão. São Paulo: Parábola Editorial, [2008] 2009.

MOITA LOPES, Luis P. Linguística aplicada e vida contemporânea: problematização dos construtos que têm orientado a pesquisa. In: . (Org.) Por uma linguística aplicada INdisciplinar. São Paulo: Parábola Editorial, [2006] 2008. p. 85-107.

PUREN, Christian. La didactique des langues face à l'innovation technologique. In: Usages des Nouvelles Technologies et Enseignement des Langues Étrangères Conferences, 2., 2001. L'Université Technologique de Compiègne. Actes des Colloques... Compiègne: La Bibliothèque de l'Université Technologique de Compiègne, 2001. p. 3-14. Disponível em: <http://www.utc.fr/ untele/volume2.pdf>. Acesso em: 21 fev. 2012.

TELLES, João. O projeto telemático "Teletandem Brasil: línguas estrangeiras para todos". In: BENEDETTI, Ana M.; CONSOLO, Douglas A.; VIEIRA-ABRAHÃO, Maria H. Pesquisas e ensino e aprendizagem no teletandem Brasil: línguas estrangeiras para todos. Campinas: Pontes Editores, 2010.

WANG, Feng; HANNAFIN, Michael J. Design-based research and technology-enhanced learning environments. Educational Technology Research and Development, v. 53, n. 4, p. 5-23, 2005. Disponível em: <http://link.springer.com/article/10.1007\%2FBF02504682\#page-1>. Acesso em: 22 set. 2013.

WEBER, Corinne. Pour une didactique de l'oralité: enseigner le français tel qu'il est parlé. Paris: Didier, 2013.

Submetido em: 29/09/2014 Aceito em: 15/05/2015

Title: Conversations between future French teachers: a proposal of design for on-line oral interaction practice in initial training 